\title{
The Information Needs of Clinicians: a Study of the Doctors Nova Scotia Clinical Library ${ }^{1}$
}

\author{
Patricia J. Lee
}

\begin{abstract}
Background: The Clinical Library (CL) is a virtual library of books, journals, drug information, and patient information. It has no hard copy books or journals to lend. Objectives: On the 10-year anniversary of the CL, feedback from information skills training indicated a need for a user assessment survey to ensure that the CL continues to meet the medical information needs of the modern clinician. The study was conducted to assess the level of electronic information use, the geographical distribution of users, and the frequency of use by various clinical practitioners. The study also contained a survey of health librarians in the United Kingdom to assess whether our information strategies are in line with international practices and needs. Methods: External consultants were hired to conduct interviews and a survey among the membership and to perform an environmental scan of Canadian and U.S. services. A series of interviews was conducted by the health librarian at health libraries in the U.K. Results: Sixty-two percent of survey respondents said they access information to help inform patient diagnosis or treatment at least every $2-3$ days, $40 \%$ of respondents regularly use web-based medical information services, and $46 \%$ of respondents used the CL as part or all of their electronic search strategy. The use of the CL varied widely depending on the location of respondents and their access to a health library. Respondents in rural areas and those unaffiliated with hospital libraries were more likely to use the virtual CL. Family practitioners showed the most familiarity with the CL offerings and reported the highest use of the CL (66.7\% of respondents). A significant minority of respondents found the CL difficult to navigate. The U.K. arm of the study showed that services offered there were similar to those offered by the CL. Conclusions: Based on the findings, the CL remains a vital service for members. The CL should maintain its services for members and make the user interface easier to use. A majority of clinicians are seeking evidence to support decisions about patient care. The use of web-based resources, including journals and textbooks, is growing. The CL is meeting the needs of a significant portion of respondents, mainly family physicians. The U.K. study found that librarians there offer similar services to those offered by the CL and that, based on their use, U.K. librarians expect to be offering these services for some time to come. The CL must look for synergies and duplication with affiliated libraries and find ways to collaborate and promote services.
\end{abstract}

\section{Introduction}

The Clinical Library (CL) was launched by Doctors Nova Scotia (DNS) in 2000 for provincial physicians, surgeons, and students; mostly for rural physicians who do not have access to a local hospital or university health library. Of the approximate 1800 members in 2000, roughly $40 \%$ lacked access to a local health library. The main library services were to provide: $(i)$ a core collection of books, journals, drug information, and patient information; (ii) information skills training (some face to face, some online); (iii) literature searches; (iv) information requests; and $(v)$ referral services.

The services were well received by members, and over the years the face-to-face information skills workshops reached approximately one-third of the members.
Feedback was provided through workshop evaluations. However, it was clear there was value in obtaining wider input about all services offered through a survey distributed to as many members as possible.

\section{Literature review}

The ways physicians and surgeons use information has been well documented in the literature [1-3]. Studies have focused on why clinicians seek information [4-6]. In Davies' 2007 review of the international literature from 1996-2006, she described the type of information needs clinicians have, barriers they encounter, and which sources were used [7]. She found that, even then, traditional faceto-face communication and use of print sources was still prevalent among qualified medical staff in the clinical

Patricia J. Lee. ${ }^{2}$ Librarian, Doctors Nova Scotia, 25 Spectacle Lake Drive, Dartmouth, NS B3B 1 X7.

${ }^{1}$ This paper is peer-reviewed.

${ }^{2}$ Corresponding author (e-mail: pat.lee@doctorsns.com). 
setting. Again in 2007, Ely described the kinds of patient care questions physicians can't answer [8]. Also in 2007, Gonzalez reviewed 3500 patient consults in Spain to identify the most frequent questions asked by physicians there [9]. The cause of a certain symptom was the most frequently asked question according to their study. They also found that only one in five questions was followed up. In 2009, Hughes looked at the use junior physicians made of web 2.0 for information seeking [10]. He found that Google and Wikipedia were used by $80 \%$ and $70 \%$ of respondents, respectively, and that their credibility risks were mitigated by cross checking. Also in 2009, Prendiville found that web-based pediatric resources were increasingly significant in this area of medical practice and that many pediatricians believed that patient care depended on these resources [11].

\section{Objectives}

The aim of the study was to get a better understanding of provincial clinicians' current information practices and to determine whether the CL meets the demands of the modern clinician.

Primary objectives included obtaining information on: how widespread the use of electronic medical information sources was, how often the CL was used to meet clinicians' needs, whether geographical location and access to a hospital library impacts the use of the CL, the familiarity with the spectrum of resources and services offered by the $\mathrm{CL}$, the ease of use of the current CL interface, and whether certain practitioner specialists were more or less familiar with the CL.

\section{Methods}

\section{Environmental scan}

Consultants performed an environmental scan of other comparable or leading-edge virtual information services for medical or other professional groups from which we could gain ideas and insights. We looked for services offered by professional associations and others that provide information resources as well as services that inform or support decision making and problem solving. The consultants contacted a cross-section of DNS members in a series of 18 interviews (from December 2010 to January 2011). Specialist and family practitioners from urban and rural settings were contacted from a list provided by the clinical librarian. Ten family practitioners, five specialists, and three students were interviewed. They were asked about their information needs currently and in the near future. The interviews explored how physicians inform decisions regarding patient care, how they keep current in their area of practice, and how they learn about public health issues. This preliminary study highlighted issues of importance for members which were followed up in the survey questions.

Interviewees were asked how they find information for questions about patient care, keeping up to date in their area of practice, keeping up to date on current and highprofile public health issues (e.g., mumps epidemic in 2007), current public health issues and community health (e.g., obesity, physical activity), research, and other topics as identified by the respondent.

Interviewees were also asked to identify the types of information they require for their main responsibilities and preferred sources. The possible sources included: informal discussion with colleagues, professional journals and reference material in their office or clinic, information provided from pharmaceutical companies or other commercial sources, internet searches, and information services and databases available online such as the CL and the Canadian Medical Association's (CMA) online resources for members.

Finally, interviewees were asked about their information challenges, specifically about what types of information are most difficult for the respondent to locate or acquire.

\section{Survey}

The survey was developed by the library steering committee and the consultants, and it was based on the responses from the interviews. The survey was administered by the consultants. In March 2011, both email and fax were used to distribute the survey as widely as possible among the membership of 10 provincial health districts in Nova Scotia.

Surveys were also available on the website. Email notices of the survey were sent to all members. Consent was assumed through submission of a completed survey. The goal was to have as many surveys as possible completed and returned.

\section{U.K. study}

To get more detail about the practice and planning of health libraries further afield, the clinical librarian conducted a number of interviews with Health Librarians in the U.K. The U.K. was chosen because it has a strong library system within the National Health Service (NHS) that appears to offer insights of value to us. Also, there is no language barrier and it is relatively accessible geographically. Initial contact was made with Richard Osborn, NHS London Library Lead, who suggested visiting a cross-section of health libraries. Interviews were arranged with four professional associations (The British Medical Association, The Royal College of General Practioners, The Royal College of Obstetrics and Gynecology, and the Royal College of Surgeons), 1 hospital library (Whipps Cross Hospital Libarary), and 3 London university medical school libraries (Imperial College, University College, and Kings College).

In the U.K. interviews, health librarians were asked:

1. What are the most popular services in your library?

2. What are the strengths and weaknesses of these services?

3. What are the challenges of the services?

4. What initiatives have been taken to address these challenges?

5. What are your expectations about the most popular services in 5 years?

6. What other comments can you make relative to these issues? 


\section{Results}

\section{Environmental scan}

The environmental scan of comparable virtual information services for medical associations and groups in North America showed that the CMA library offers similar (mainly) family practice resources and services to those offered on the CL site, and the College of Family Physicians of Canada (CFPC) library offers an extensive search service. However, neither of these libraries offers information skills training.

\section{Interviews}

A majority of participants and respondents described needing information about diagnosis, therapy, and prognosis. Several interview participants mentioned a lack of awareness of the CL. Others expressed concern that the CL was not easy to use.

\section{Survey}

Of the 3785 physicians and surgeons surveyed in April $2011,644(17 \%)$ responded to the survey, a significant uptake given the demands on busy clinicians.

A key question in the survey was the frequency with which clinicians consulted information services to help inform patient diagnosis or treatment. As shown in Figure 1, the majority $(62 \%)$ of respondents said they access information services (e.g., literature searches, article requests) to help inform patient diagnosis or treatment at least every 2-3 days.

Another key question related to the sources used to access this information. The results shown in Table 1 demonstrate that web-based data retrieval is increasingly common. We found that $40 \%$ of respondents regularly use web-based medical information services, $27.6 \%$ use medical journals on the web "all the time" to assist with diagnosis or treatment, $38 \%$ use them "most of the time", and $19 \%$ use them "much of the time". We found that $21.3 \%$ of respondents conduct internet searches "very often" for diagnosis or treatment using search engines such as Google and general web sites such as Wikipedia, $32 \%$ use them "most of the time" and $25 \%$ use them "much of the time" (see data from Table 1).

We also asked about the use of DNS CL. Among the respondents who use web-based medical information services, $46 \%$ used the CL as a part or all of their search strategy.

Fig. 1. Frequency of use of information services for patient care.



The use of the CL varied widely depending on the location of respondents and their access to a health library. For example, $93.3 \%$ of respondents from Pictou County used the CL, whereas only $62.2 \%$ of respondents from Cape Breton district used the CL. Respondents with hospital privileges were less likely to use the CL $(40 \%$ never use) than respondents without hospital privileges (35.3\% never use). This likely reflects the easy access of clinicians with hospital privileges to hospital libraries. Respondents in the Capital Health District, which includes the two major teaching hospitals, were most aware of the CL offerings but least likely to use the CL (Capital Health: $59 \%$ use, and IWK Health Centre: $46.1 \%$ use). This likely reflects their access to their own hospital libraries and their access to the University Health Sciences Library.

It is family practitioners, especially in rural districts, who lack access to information from a health library. They have a greater need for health information so it was not surprising that the family practice cohort of the survey showed the most familiarity with the CL offerings and were the survey group that reported the highest use of the CL (66.7\% of respondents).

A survey question relating to ease of use of the CL was included, as this was thought to be a major factor in the widespread use of this service. Respondents were asked to rate the ease of finding the information they require as good, satisfactory, or poor. The majority $(73 \%)$ of respondents rated this element of the CL as good to satisfactory, whereas $21 \%$ rated the ease of finding specific information on the CL as poor. Interestingly, 91\% rated the training and support to use the CL resources as good to satisfactory. Although most respondents found the CL easy or satisfactory to use, a significant minority found it difficult to use.

Comments from the interviews and open comments on the survey indicated that, although many members were familiar with aspects of the CL resources, many were not familiar with other important resources such as practice guidelines and patient fact sheets, and services such as the literature searching service.

Open comments from the survey emphasized the need to improve the profile and usability of the library. The comments also indicated that it would be better to focus the CL in its areas of strength, such as providing information for family practitioners.

\section{U.K. study}

From the U.K. interviews, we learned that the CL services were widely available and that U.K. librarians expect a continued need of these services well into the future. Specific services highlighted were: face-to-face information skills training, literature searches, information requests, and referral services.

The U.K. survey indicated that information skills training was of significant importance going into the future.

\section{Conclusions}

The environmental scan of comparable virtual information services found that the CMA library offers similar 
Table 1. Survey responses to the question "When you need information to assist with a diagnosis or treatment of a patient, how frequently do you use each of the following sources of information?"

\begin{tabular}{|c|c|c|c|c|c|c|c|}
\hline & 1 Never $(\%)$ & $2(\%)$ & $3(\%)$ & $4(\%)$ & $\begin{array}{c}5 \text { All the time } \\
(\%)\end{array}$ & $\begin{array}{c}\text { Response } \\
\text { total }\end{array}$ & $\begin{array}{c}\text { Average } \\
\text { score }\end{array}$ \\
\hline Talk with colleagues & $6(.93)$ & $64(9.95)$ & $149(23.17)$ & $215(33.44)$ & $209(32.5)$ & 643 & 3.87 \\
\hline Medical journals in print & $100(15.53)$ & $201(31.21)$ & $154(23.91)$ & $137(21.27)$ & $52(8.08)$ & 644 & 2.75 \\
\hline $\begin{array}{l}\text { Medical texts in print } \\
\text { (e.g., Harrison's, etc.) }\end{array}$ & $55(8.54)$ & $199(30.9)$ & $210(32.61)$ & $133(20.65)$ & $47(7.3)$ & 644 & 2.87 \\
\hline $\begin{array}{l}\text { Internet searches (e.g., Google, } \\
\text { Wikipedia, etc.) }\end{array}$ & $31(4.82)$ & $107(16.64)$ & $160(24.88)$ & $208(32.35)$ & $137(21.31)$ & 643 & 3.49 \\
\hline Medical journals on the web & $41(6.37)$ & $51(7.92)$ & $126(19.57)$ & $248(38.51)$ & $178(27.64)$ & 644 & 3.73 \\
\hline Medical texts on the web & $67(10.4)$ & $109(16.93)$ & $151(23.45)$ & $189(29.35)$ & $128(19.88)$ & 644 & 3.31 \\
\hline $\begin{array}{l}\text { Web-based medical information } \\
\text { services (e.g., UpToDate, etc.) }\end{array}$ & $65(10.09)$ & 77 (11.96) & $88(13.67)$ & $163(25.31)$ & $251(38.98)$ & 644 & 3.71 \\
\hline
\end{tabular}

Note: Frequency of use was rated on a scale from 1 to 5 , where 1 means "not a source of information I use, would never use", and 5 means "a primary source of information, use it all of the time".

family practice resources and search services to those offered on the CL, and the College of Family Physicians of Canada library offers an excellent search service. However, neither of these national services is able to provide the local library referral service that is needed for specialists, nor do the national services offer information skills training, which the U.K. study identified as an important service.

This scan suggests that because DNS offers information resources similar to the CMA library, it is worthwhile exploring whether to change the resources offered so that members have access to more point of care tools and support for mobile devices. Similarly, it is important to consider whether this duplication of resources or offering of different sources is worthwhile or whether our members would be better served by offering only library search and referral services without the e-resources. A collection analysis and study of our users' access to resources will be conducted to address this question.

A key conclusion drawn from the survey is that a majority of respondents are seeking evidence to support decisions about patient care, based on the finding that $62 \%$ report using information services to inform decisions about patient care every $2-3$ days. In addition, it indicates that a majority of respondents use information services to find the information they need. This underlines the need for information services. It is also important to note that the use of web-based resources including journals and online textbooks is growing. Clearly there is a need for online resources. Careful study of users' access to these resources is essential to determine whether the DNS CL should maintain, modify, or eliminate its collection.

Because $46 \%$ of respondents reported using the CL as part or all of their search strategy, it appears that the CL is meeting the needs of a significant portion of respondents. The question still remains whether the CL in its present state offers the best value to its users. A more focused study will soon be undertaken to address this issue.

Survey responses indicated a wide variety of CL users among clinicians, depending on their location and access to a hospital or university health library. However, among these users, family practitioners are the most aware of the $\mathrm{CL}$ and they are the most frequent users. This is logical as more family practitioners than specialists work in the community and do not have access to a hospital library. In addition, the CL has more family medicine resources than resources for specialists.

Most specialists have hospital privileges and some hospitals have hospital libraries. Also, the lack of many specialist journals available on the CL was noted. Consequently, we conclude that it is mainly family physicians that use the CL.

A significant minority of respondents found the CL hard to use, and a greater percentage of users were not familiar with some of the CL services such as literature searches and resources such as practice guidelines and patient fact sheets. This suggests a need to improve the CL profile and usability.

This study resembles the studies by Case [4], Cullen [5], and Gorman [6]. Case found that MDs need to know about medical practice and research findings about patient conditions. Cullen found that clinicians need recent information on both common and rare diseases. Gorman developed a taxonomy of types of information needed, including patient data, population statistics, medical knowledge, logistical information, and social influences such as local practice. This study found that clinicians need information about diagnosis, therapy, and prognosis and a majority of survey respondents look for it every 2-3 days.

The U.K. study found that librarians there offer similar services to those offered by the CL and that, based on their 
use, U.K. librarians expect to be offering these services for some time to come. Insights gained from our British counterparts and their national library service include the benefits of libraries collaborating on programs and resources. The NHS has had a national collection of resources for all health professionals for many years, and they have a highly developed infrastructure to ensure that individual health libraries have support for programs and initiatives for library users. Richard Osborn and the London team procure information for all health libraries in London and coordinate with other parts of England. Four national teams coordinate information provision nationally for England, Scotland, Northern Ireland, and Wales.

Based on the information obtained from the U.K. study, possible initiatives for the CL to consider include:

(i) introducing information skills and e-learning modules in a short, interactive format, for example subject guides indicating where to find different types of information; developing a good search strategy; and database searching;

(ii) determining ways to interact with departments within DNS and outside organizations to improve the library profile and programs, for example, consider collaborating within DNS or with another organization to see if there are any common interests in developing an e-learning program; and

(iii) incorporating results of this study into the CL communications and marketing plan so DNS managers and the board understand the value of library services and information skills for members.

\section{Acknowledgements}

The research for this paper was financially supported by Doctors Nova Scotia. In developing the ideas presented here, I have received helpful input from Dr. Jackie MacDonald.

\section{References}

1. Kosteniuk J, Morgan D, D'Arcy C. Use and perceptions of information among family physicians: sources considered accessible, relevant and reliable. J Med Libr Assoc. 2013; 101(1):32-7. doi: 10.3163/1536-5050.101.1.006.

2. Chatterley T, Storie D, Chambers T, Buckingham J, Shiri A, Dorgan M. Health Information support provided by professional associations in Canada. Health Info Libr J. 2012; 29(3):233-41. doi: 10.1111/j.1471-1842.2012.00993.x.

-3. Younger P. Internet-based information - seeking behaviour amongst doctors and nurses; a short review of the literature. Health Info Libr J. 2010;27(1):2-10. doi: 10.1111/j.14711842.2010.00883.x.

4. Case D. Looking for information. A Survey of Research on Information Seeking, Needs, and Behavior. Amsterdam: Elsevier / Academic Press; 2007. p. 423.

5. Cullen RJ. In search of evidence: Family practitioners' use of the internet for clinical information. J Med Libr Assoc. 2002;90(4):370-9.

6. Gorman PN. Information needs of physicians. Journal of the American Society of Information Science. 1995;46:729-36.

7. Davies K. The information-seeking behaviour of doctors; a review of the evidence. Health Info Libr J. 2007;24(2):78-94. doi: 10.1111/j.1471-1842.2007.00713.x.

8. Ely J. Patient care questions physicians can't answer. Journal of the American Medical Informatics Associations. 2007;14(4):407-14. doi: 10.1197/jamia.M2398.

-9. Gonzalez-Gonzalez AI, Dawes M, Sanchez-Mateos J, Riesgo-Fuertes R, Escortell-Mayor E, Sanz-Cuesta T, Hernandez-Fernandez T. Information needs and information-seeking behavior of primary care physicians. Ann Fam Med. 2007;5(4):345-52. doi: 10.1370/afm.681.

10. Hughes B, Joshi I, Lemonde H, Wareham J. Junior physician's use of web 2.0 for information seeking and medical education: A qualitative study. Int $J$ Med Inform. 2009;78(10):645-55. doi: 10.1016/j.ijmedinf.2009.04.008.

11. Prendiville TW, Saunders J, Fitzsimons J. Information seeking behaviour of pediatricians accessing the web. Archives of Disease in Childhood. 2009;94(8):633-5. doi: 10.1136/adc.2008.149278. 